\title{
Recommendations on Recent Proposals for the Classification of Shigellae
}

\author{
DON J. BRENNER $\dagger$ \\ Molecular Biology Laboratory, Division of Bacterial Diseases, Center for Infectious Diseases, Centers for Disease \\ Control, Atlanta, Georgia 30333
}

\begin{abstract}
A number of recent proposals to change the classification of shigellae were studied by the International Committee on Systematic Bacteriology Subcommittee on the Taxonomy of Enterobacteriaceae, which recommended adoption of the following proposals: (i) subdivision of Shigella flexneri serotype 5 into two subserotypes, 5a and 5b; (ii) reduction of the number of $S$. flexneri serotype 3 subserotypes from three to two; (iii) that Shigella sp. provisional serotype $2000-53$ is not a Shigella, but an Escherichia coli; (iv) that provisional Shigella sp. serotypes $3873-50$ and $3341-55$ be added to the Shigella serotyping scheme as Shigella dysenteriae serotypes 11 and 12; (v) that provisional Shigella sp. serotypes 2710-54 and 3615-53 be added to the Shigella serotyping scheme as Shigella boydii serotypes 16 and 17; (vi) that Shigella sp. strain E 10163 and similar strains be added to the Shigella serotyping scheme as $S$. boydii serotype 18; and (vii) that provisional Shigella sp. serotype 1621-54 retain its provisional status pending study of additional strains.
\end{abstract}

In 1979, Petrovskaya and Khomenko made eight proposals that dealt with the classification of Shigella serotypes (6). In 1980, Gross et al. proposed a new serotype in Shigella boydii (2). The International Committee on Systematic Bacteriology Subcommittee on the Taxonomy of Enterobacteriaceae (the Subcommittee) studied these nine proposals. The recommendations of the Subcommittee are given below.

The first proposal of Petrovskaya and Khomenko was to subdivide Shigella flexneri serotype 5 into two subserotypes, $5 \mathrm{a}$ and $5 \mathrm{~b}$. Subserotype $5 \mathrm{a}$ would have the antigenic formula $V: 3,4$, and subserotype $5 \mathrm{~b}$ would have the antigenic formula $\mathrm{V}: 7,8$. This proposal is supported by data published by Simmons $(3,4,7)$ and by Petrovskaya and Bondarenko (5) and was confirmed by M. Toucas, National Shigella Centre of France (personal communication). The Subcommittee recommends adoption of this proposal.

The second proposal of Petrovskaya and Khomenko was to reduce the present designation of three subserotypes of $S$. flexneri 3 to two subserotypes that differ in the presence of III:7,8. In the present system subserotype $3 \mathrm{a}$ is III:6,7,8, subserotype $3 \mathrm{~b}$ is III:3,4,6, and subserotype $3 \mathrm{c}$ is III:6. These formulas would become $(3,4), 6,7,8$ for subserotype $3 a$ and $(3,4), 6$ for subserotype $3 \mathrm{~b}$. The third proposal of Petrovskaya and Khomenko was to reverse the presently used designations for subserotypes $3 \mathrm{a}$ and $3 \mathrm{~b}$. In the proposed system, subserotype 3 a would be III:(3,4),6 and subserotype $3 \mathrm{~b}$ would be III: $(3,4), 6,7,8$. The 3,4 reaction is weak or unstable or both and is often difficult to interpret. The Subcommittee recommends adoption of the proposal to recognize only two subserotypes in $S$. flexneri 3 by combining subserotypes $3 \mathrm{~b}$ and $3 \mathrm{c}$, but does not agree with reversing the designations for subserotypes $3 \mathrm{a}$ and $3 \mathrm{~b}$. The reason for the proposal to reverse the subserotype $3 a$ and $3 b$ designations was to have the subserotypes conform with the subserotype designations in $S$. flexneri serotypes $1,2,4$, and 5 , where the a subserotypes have factors $1,3,4$ and the $b$ serotypes have factors 7,8. Although it is logical, the Subcommittee recommends rejection of this proposal because reversing the subserotype designations would have no practical value. In fact, this proposal would cause a great deal of

$\dagger$ For the International Committee on Systematic Bacteriology Subcommittee on the Taxonomy of Enterobacteriaceae confusion by changing the designations that have been used and universally accepted for almost 35 years (1).

The fourth proposal of Petrovskaya and Khomenko was to transfer $S$. flexneri serotype 6 to Shigella boydii. They cited serological, biochemical, and genetic data to support this proposal. This question was discussed by the Subcommittee Working Group on Shigella at the 1973 International Congress of Bacteriology. The Working Group concluded that "although there is serological, chemical, and genetic evidence in favor of excluding $S$. flexneri 6 from $S$. flexneri, the historical reasons make exclusion untenable"' (8). Therefore, this change would have no practical value and would cause confusion by altering a well-accepted system. The Subcommittee reaffirms its 1973 opinion and recommends that this proposal be rejected.

The fifth proposal of Petrovskaya and Khomenko was to transfer provisional Shigella sp. serotype 2000-53 to Escherichia coli. These authors presented data showing that this serotype had the $E$. coli O:6 antigen and that it was resistant to a Shigella-specific bacteriophage. Unpublished data from the World Health Organization International Collaborating Shigella Center (H. G. Wathen-Grady, personal communication) on serotyping and biochemical reactions of two serotype 2000-53 strains led to the conclusion that they were $E$. coli rather than Shigella. The Subcommittee recommends adoption of this proposal.

The sixth proposal of Petrovskaya and Khomenko was that provisional serotypes $3873-50$ and $3341-55$, on the basis of their cultural and biochemical properties, be added to the Shigella serotyping scheme as Shigella dysenteriae serotypes 11 and 12, respectively. Wathen-Grady (unpublished data) has shown that these serotypes are unique and that they are biochemically most similar to $S$. dysenteriae. The Subcommittee recommends adoption of this proposal.

The seventh proposal of Petrovskaya and Khomenko was that provisional Shigella sp. serotypes 2710-54 and 3615-53, on the basis of their cultural and biochemical properties, be added to the Shigella serotyping scheme as $S$. boydii serotypes 16 and 17 . Wathen-Grady (unpublished data) has also shown that these serotypes resemble $S$. boydii biochemically and that they are serologically distinct from other $S$. boydii serotypes. Gross et al. proposed that 11 strains isolated from feces of patients with diarrhea be regarded as a provisional serotype of $S$. boydii. The reference strain of this group is 
strain E 10163. Strain E 10163 had a serological crossreaction with provisional Shigella sp. serotype 3341-55, but this cross-reaction was removed by adsorption. Biochemically, the strain E 10163 group was mannitol positive, a reaction typical of $S$. boydii strains, whereas serotype 334155 was mannitol negative (2). These observations were confirmed by Wathen-Grady (unpublished data). The Subcommittee recommends that provisional serotype $2710-54$ be added to the Shigella serotyping scheme as $S$. boydii serotype 16, that provisional serotype $3615-53$ be added as $S$. boydii serotype 17, and that provisional serotype $\mathrm{E} 10163$ be added as $S$. boydii serotype 18.

The eighth proposal of Petrovskaya and Khomenko was to retain the provisional status of provisional Shigella sp. serotype 1621-54. This provisional serotype has a serological cross-reaction with $S$. boydii 12 , but it is raffinose positive, an atypical reaction for $S$. boydii. The Subcommittee recommends that, pending further study, serotype 1621-54 remain as a provisional Shigella serotype.

\section{ACKNOWLEDGMENTS}

The Subcommittee on the Taxonomy of Enterobacteriaceae is indebted to H. G. Wathen-Grady, Enteric Laboratory Section, Division of Bacterial Diseases, Centers for Disease Control, Atlanta, Ga., and to M. Toucas, National Shigella Centre, Enterobac- teriaceae Unit, Institut Pasteur, Paris, France, for consultation on these proposals.

\section{LITERATURE CITED}

1. Ewing, W. H. 1949. Shigella nomenclature. J. Bacteriol. 57:633638.

2. Gross, R. J., L. V. Thomas, and B. Rowe. 1980 . New provisional serovar (E 10163) of Shigella boydii. J. Clin. Microbiol. 12:167169.

3. Kenne, L., B. Lindberg, K. Petersson, E. Katzenellenbogen, and E. Romanowska. 1977. Structural studies of the Shigella flexneri variant $\mathrm{X}$ type $5 \mathrm{a}$ and type $5 \mathrm{~b} \mathrm{O}$-antigens. Eur. J. Biochem. 76:327-330.

4. Kenne, L., B. Lindberg, K. Petersson, E. Katzenellenbogen, and E. Romanowska. 1978. Structural studies of Shigella flexneri Oantigens. Eur. J. Biochem. 91:279-284.

5. Petrovskaya, V. G., and V. M. Bondarenko. 1977. Recommended corrections to the classification of Shigella flexneri on a genetic basis. Int. J. Syst. Bacteriol. 27:171-175.

6. Petrovskaya, V. G., and N. A. Khomenko. 1979. Proposals for improving the classification of members of the genus Shigella. Int. J. Syst. Bacteriol. 29:400-402.

7. Simmons, D. A. R. 1971. Immunochemistry of Shigella flexneri $\mathrm{O}$ antigen: a study of structural and genetic aspects of the biosynthesis of cell-surface antigens. Bacteriol. Rev. 35:117-148.

8. Subcommittee on Enterobacteriaceae, International Committee on Systematic Bacteriology. 1974. Minutes of the meeting, 2 September 1973. Int. J. Syst. Bacteriol. 24:385-387. 